\title{
ANTECEDENTES Y GÉNESIS DE LA PRIMERA GRAMÁTICA CASTELLANA
}

\author{
Manuel Antonio Quirós R.
}

\begin{abstract}
This paper focuses on the cultural and linguistic backgrounds for the genesis and elaboration of the first Spanish grammar by Antonio de Nebrija (1492): the role played by Classical Latin on the Romance Languages revaluation, mainly in regard to the "imitatio" and "aemulatio" in the Renaissance; the predecessor works by both the provençal grammars and Dante's "De vulgari eloquentia": the idiomatic ideas by the Humanists, and Nebrija's humanism.
\end{abstract}

\section{Introducción}

La época prenebrijiana es contemporánea a la penetración e inicio del Humanismo en España: 1400-1474. Se caracteriza por un marcado interés hacia la cultura clásica grecolatina y la italiana. De 1474 a 1525 se da el período de transición del castellano medieval al preclásico.

En este artículo se esboza la génesis de la primera gramática castellana, escrita por Antonio Martínez de Xarana (1444-1522), latinizado en Elio Antonio de Nebrija (de la antigua "Nebrissa Veneris", hoy, Lebrija, Guadalquivir abajo):

¿Cuáles fueron los antecedentes históricos: educativos, culturales, y, sobretodo, filológico-lingüísticos que impulsaron al nebrijense a elaborarla?

¿Cuáles, las concepciones idiomáticas que se habían desarrollado en Italia y que parcialmente desembocaron en el Humanismo-Renacimiento?

¿Cómo eran las ideas sobre el romance castellano en la misma época de Elio Antonio?

¿Cómo se manifiesta el Humanismo del autor de la primera gramática castellana?

Y principalmente, ¿qué papel desempeñó el latín clásico en la revalorización del romance?

Las respuestas a estas preguntas implican la exclusión, en este trabajo, de los aspectos internos y estructurales de la gramática de Elio Antonio de Nebrija. 


\section{Génesis de la gramática del nebrijense}

En el mes y año en que el Almirante zarpaba del puerto sureño de Palos y emprendía su sueño de una nueva vía marítima hacia el lejano Oriente, en la sede de la segunda universidad más antigua de España, Salamanca (ca.1251), salía a la luz pública la primera gramática castellana, con la inmensa fortuna de que, para 1492, ya se había establecido en Valencia (1474) la imprenta de Gutemberg.

El trabajo gramatical de Nebrija se puede enmarcar en un contexto temático y de discusión de ideas humanísticas que afloraban desde Italia: la patria del latín. Por lo cual no deja de lado el aporte indirecto de otras gramáticas, o especies de gramáticas, neolatinas, que habían sido elaboradas en otros países de la Romania. ¡Elio Antonio de Nebrija no constituye un caso aislado!

Por tal motivo, presento, primero, las obras gramaticales, incluso, filológicas, precursoras de la gramática nebrijiana; soslayo las contempráneas a éste y esbozo las principales ideas, preámbulo del trabajo de Elio Antonio.

\subsection{Obras y autores precursores, o coetáneos de Nebrija}

- La tradición gramatical grecolatina.

- Las gramáticas occitanas o prevenzales.

- El "De vulgari eloquentia" de Dante Alighieri.

- Los coetáneos de Antonio de Nebrija.

- Lo original y auténtico de Elio Antonio.

\section{La tradición gramatical grecolatina}

Los estudios gramaticales de las lenguas romances, e, incluso de otras lenguas, como el alemán y el inglés, poseen una fundamentación teórica latina: Prisciano, Diomedes, Donato y Quintiliano, quienes, a su vez, se basan en las disquisiciones teóricas de los griegos. Tal tradición gramatical se ha perpetuado en el transcurso de la Edad Media; y sin ella, los estudios gramaticales modernos apenas estarían en pañales.

Durante la Edad Media, la gramática era parte del Trivium y tuvo cuatro períodos: las compilaciones de Donato y de Prisciano, el trabajo de Alcuino, en pleno Renacimiento carolingio, las escuelas catedralicias y la reforma prehumanista. Su máxima actividad consistió en cuidar la pureza del latín sobre la base de la literatura de éste.

\section{Las gramáticas occitanas o provenzales}

En la esfera romance, abren brecha los tratados para aprender a escribir la koiné occitana, la de los poetas trovadores provenzales, sureños de Francia. Fueron los trovadores los primeros en poetizar en una lengua neolatina, luego del desastre del 474: caída del Imperio Romano. La importancia trovadoresca radica en que, al acto propiamente creador, se aunaba el trabajo crítico-filológico: glosarios, rimarios, bibliografías y hasta gramáticas. 


\section{Razós de trobar}

Ramón Vidal de Besalú es el autor de la primera gramática en una lengua romance. La elaboró para enseñar a escribir la lengua de los trovadores. Este catalán se proponía una "dreicha maniera de trobar": un buen modo de poetizar. Pero su realización no es ningún tratamiento sistemático como sí lo es la gramática de Nebrija.

\section{Donatz proensals}

Este tratado fue escrito en Italia, en 1243, por Uc Faidit, para uso de los habitantes de esta península. La intención purista se basa en el famoso gramático antiguo, Donato: una adaptación de su "Ars Minor". La gramática está completada por un extenso glosario de la rima.

\section{Doctrina d'acort}

Esta obra, redactada por Terramagnino de Pisa, en Cerdeña, entre 1282 y 1296, es una adaptación versificada de las "Razós de trobar".

\section{Regles de Trobar}

Tales reglas están formadas por una gramática, abundantes citas de los trovadores y observaciones sobre versificación y poética, con el fin de iniciarse en el "saber trovar". Su autor es un catalán, Jofré de Foixà, quien la redactó en Sicilia, entre 1289 y 1291.

\section{Mirall de trobar}

Este tratado, de contenido gramatical y retórico, está provisto de ejemplos de buenos trovadores. Su autor, de principios del siglo XIV, fue Berenguer de Anoya (Inca, Mallorca).

\section{Leys d'amors}

El jurista tolosano, Guilhem Moliner, escribió estas leys por iniciativa de la "Gaya Sciencia”. De todos los tratados anteriores, es el más extenso, pues está dotado de una gran riqueza gramatical, retórica, estilística y versificatoria.

Pero, a favor de Nebrija, obra el hecho, de que, en la finalidad de tales elaboraciones, el conocimiento gramatical está supeditado a la creación literaria; en cambio, el trabajo de Nebrija lo está a la lingüística; por eso su gramática se basa en hechos lingüísticos reales de su época, y no tanto en la lengua literaria.

\section{El "De vulgari eloquentia"}

Entre 1303 y 1305, el toscano, Dante Alighieri, escribe este tratado, en donde, no sólo intuye la existencia del griego y de las lenguas germánicas, sino hasta elabora una clasificación 
de los idiomas romances según la partícula afirmativa de éstas: lengua de oc, provenzal; lengua de oil, francés; lenguas del sí: italiano y español.

En tal tratado, Dante plantea, en forma crítica, la situación de las lenguas vernáculas, y elogia su importancia como idiomas hablados, aprendidos inconscientemente desde la niñez, frente al otro, el latín, aprendido conscientemente mediante reglas gramaticales; y entonces, el autor de la Divina Comedia defiende y alaba el empleo de una lengua italiana que sea común y general para todos los habitantes peninsulares, donde se refleje la unidad de Italia, en el plano literario.

En el poeta florentino, es patente la diglosia medieval y se nota un cambio de mentalidad en las concepciones idiomáticas sobre la nacionalidad de las variedades románicas hasta entonces conocidas, en contraposición a la internacionalidad del latín medieval: lengua universitaria y eclesiástica.

\subsection{Obras gramaticales coetáneas a la gramática de Nebrija}

\section{Grammaticheta}

Esta obrita, de 1529, se debe a Gian Giorgio Trissino, el opositor italiano de Pietro Bembo:

\section{Prose della volgar lingua}

Con este tratado, el cardenal Bembo se opone al anterior y ofrece sus planteamientos en torno a la "Questione della lingua" (1525): la discusión suscitada en Italia sobre el latín y la lengua vulgar digna de ser usada por los escritores literarios en italiano: la "florentinidad" (florentino hablado) o "toscanidad" (toscano hablado) de la lengua italiana.

\section{Grammatica della lingua italiana} gua italiana.

León Battista Alberti compuso esta gramática en donde afirma la excelencia de la lenDeffense et illustration de la langue françoyse

Su autor, Du Bellay, declara que el francés puede ser superior al latín, griego y hebreo.

Traité de la grammere françoeze

Esta gramática fue elaborada por Louis Meigret, en 1550.

Grammatica de la lingoagem portuguesa

La primera gramática portuguesa fue escrita en 1536 por Fernando de Oliveira. 


\section{Orthographia gallica}

Este texto, anterior a los precedentes, pues es de finales del siglo XIII y principios del XIV, fue redactado en Inglaterra, en latín, para estudiar francés, idioma que había sido transplantado desde el continente por los normandos bajo la guía de Guillermo el Conquistador, y que, en el siglo XV, se constituyó en lengua de corte y de la aristocracia inglesa.

\subsection{Breve conclusión}

Las consideraciones precedentes indican cómo la obra de Nebrija debe ser comprendida en un contexto global románico, según el movimiento de renovación que operaba desde el mismo latín. Pero, paradógicamente, en los inicios mismos del Renacimiento, se presenta un nacionalismo idiomático en contra de la universalidad medieval del latín, lo cual hace pensar en un posible fracaso de los humanistas renacentistas.

El movimiento de renovación de las lenguas maternas alcanza también a países que no giran, genéticamente, en la órbita del latín, mas que lo tenían como lengua de cultura: en modo específico, me refiero a Alemania, en donde Martín Lutero (1534) imprime, en alemán, su traducción de la Biblia.

Antonio Quillis (1980) emite un criterio acertado sobre la importancia primaria de la Gramática de la lengua castellana, elaborada por Elio A. de Nebrija, consiste en ser la obra de un humanista y en ser elaborada con criterios lingüísticos que ejercieron, posteriormente, influencia para la estructuración de futuras gramáticas.

\section{Ideas forjadoras en el primer gramático castellano}

A partir de 1473, inicia la importancia de la primera grámatica castellana: el oriundo de la antigua Nebrissa Veneris regresa de Italia remozado: llega a España influenciado por el Humanismo de Petrarca y las nuevas ideas gramaticales de Pícolo della Mirandola, Valla, Bruni, Biondi y Salutati, ardientes defensores de la "Dignitas hominis", basada en las "Litteras humanas".

Elio Antonio había emprendido viaje a Italia a los 19 años, según él mismo confiesa:

Assí, que en edad de diez y nueve años io fue a Italia, no por la causa que otros van, o para ganar rentas de iglesia, o para traer fórmulas de Derecho civil y canónico, o para trocar mercaderías, mas para que por la ley de la tornada, después de luengo tiempo restituiesse en la possessión de su tierra perdida los autores del latín, que estavan ia, muchos siglos avía, desterrados de España (...) (p. 10)

Permanece 10 años en la culta Boloña, sede de la más antigua universidad de occidente, con el único interés de estudiar el latín de los autores clásicos. ¡En su época, era claro, que quien no había viajado a Italia, no sabía bien el latín!

De regreso a Salamanca, universidad de tradición boloñesa, emprende una lucha contra los españoles que habían degenerado la esencia misma del latín, su "clasicismo": 
(...) nunca dexé de pensar alguna manera por donde pudiesse desbaratar la barbaria por todas las partes de España tan ancha y luenga mente derramada (...) (p. 11)

Seguidamente, declara los motivos que lo llevaron a la universidad salmantina:

Assí, io, para desarraigar la barbaria de los ombres de nuestra nación no comencé por otra parte sino por el estudio de Salamanca, el cual, como una fortaleza, tomado por combate, no dudava io que todos los otros pueblos de España vernían luego a se rendir (...) (p. 11)

Manifiesta Piccardo (1949), citado por Antonio Quilis, (1980), en su edición de la gramática de Elio Antonio:

(...) Nebrija, al incorporarse, según vimos, a la corriente de la mejor tradición latina, se aparta de la actitud escolástica (...) Y si bien por un lado tributa a la autoridad de los viejos libros, por otro aprende a escrutar la realidad del idioma y a cimentar su trabajo en principios científicos (...) (Quilis 1980: 13)

Las ideas de los humanistas italianos sobre el latín, que repercuten en Nebrija, se fundamentan en la triste situación de tal lengua a finales de la Edad Media. Son la consecuencia de una nueva actitud crítica, producto del cambio de mentalidad que se estaba operando, y que, entre otros muchos, se manifiesta en la misma denominación para la nueva era: el Renacimiento.

A caballo de una edad a otra, la crisis escolar y universitaria repercutió, negativamente, en la educación del individuo, lo cual voy a esbozar en los siguientes apartados, tanto es así que Robelais se mofa de las sutilezas de la decadente escolástica; por eso Francisco I funda, en 1533, el Collège Royal (el Collège de France).

\section{Crisis de la escuela y del latín en la Romania y su solución}

La reflexión sobre la lengua constituye el eje central y el problema está configurado por la antonimia conservación-renovación del latín.

A finales de la Edad Media, los depositarios de la enseñanza del latín: la escuela, la universidad y la iglesia estaban en crisis por culpa de las torpes y estériles disputas teológicas y filosóficas de la escolástica tardía, principalmente, de los "nominalistas". El latín fue víctima de tal situación: se hizo esclavo del pensamiento obstruso reinante entre los intelectuales: complicado, demasiado tecnificado y especializado; en suma, un latín bárbaro recluido dentro de las mismas instituciones docentes; ;oscuro, allí donde debía ser claro! Todo lo cual engendra su decadencia, que, a su vez, engendra una actitud negativa y despectiva hacia la misma Edad Media, como escribe Vicente García de Diego (1970):

Con un sentido simplista, sin más criterio que el del valor estático de las lenguas, el clasicista latino comparaba lo más perfecto de la latinidad de oro con lo más desaliñado de los siglos medios, envolviéndolo todo en un concepto del más injusto desdén (...) (García de Diego 1970: x) 
Para la reivindicación del latín postclásico y del medievalismo, fue necesario un cúmulo de causas, que sólo en nuestros días han tenido un pleno desenvolvimiento. (ibidem)

¡Crisis en la escuela: educación y enseñanza! ¡Crisis en la cultura: el idioma! ¡Crisis en la religión: la Reforma!

Para los pensadores humanistas fue imprescindible replantearse el panorama, buscar y encontrar un antídoto: ¿dónde hallarlo?: ¡en la literatura clásica!: ¡la eximia de la época dorada augústea!: jrestaurando la "vera latinitas", se restaurarán, ipso facto, las "litterae humanae"!

¡Esta es la solución que presentan los humanistas!:

Según Valla, en cita de Avelina Carrero de la Red (1984: 31) "en latín se hallan todas las disciplinas dignas del hombre" (...) "hay que restaurar el antiguo usus loquendi basado en Cicerón y Quintiliano" (...)

Con entusiasmo, aquéllos se avalanzan sobre su propósito: restaurar el latín para restaurar el humanismo contra la nobleza, el clero y la escolástica, detentores de la escuela tradicional, de tan preciosos frutos otrora: las universidades les deben a las escuelas catedralicias su origen. Pero, en el momento en que estamos ocupados, casi todas las universidades de la Romania, con la misma Sorbona a la cabeza, padecían de un cáncer que tenía que ser extirpado.

De manera oportuna, los humanistas vienen al encuentro contra tal enfermedad: elaboran una estrecha y feliz relación entre las "litterae" y la "vera latinitas antiqua" (no la medieval) en un todo armónico que se conoce como los "studia humanitatis" o, simplemente, "humanitas".

Principalmente en Italia, tal crisis escolar-universitaria clerical, la cual repercutía en una crisis de valores humanos, impulsó a los humanistas a restaurar y a renovar amparados en la literatura clásica latina: ijusto en donde se retrataban los ejemplos de los grandes, considerados por Petrarca como los eximios modelos ideales. Los contemporáneos del poeta de Laura, o un poco posteriores, en los mismos umbrales del Renacimiento, predican que se debe recuperar la eloquentia auctorum: "i mezzi per cui l'uomo ritrovasse la sua veritá, ed il sapere della sua misura terrena: la "eloquentia dei boni autori, degli optimi": su "humanitas"; que esto traerá inherente la restauración y renovación educativa y cultural, para cuyo fin se hace imprescindible estudiar "filológicamente" el latín, y los "studia humanitatis" que engendrarán el renacimiento de las artes.

\section{Crisis de valores en la España prenebrijiana y su antídoto}

Como en casi toda la Romania, unos años antes de regresar Nebrija de Boloña, en su España, sobreviven esquemas medievales, difíciles de erradicar, pues las nuevas ideas de Elio Antonio aún no se habían difundido.

Por 800 años de luchas incesantes contra los moros, casi toda la Península Ibérica había corrido un destino diferente del de la Península Itálica, en donde sobrevivió más pura la tradición del latín, incluso, la del italiano. La reflexión del latín-romance fue más dúctil y natural en Italia que en España. En ésta, el castellano tuvo que implantarse como un dialecto "extranjero", el de los castellanos, mediante la Reconquista y subsiguiente repoblación. Alrededor de la época de Rodrigo Díaz de Vivar, los monjes cluniacenses hacen un esfuerzo para imponer la cultura 
romana y la lengua latina en contra de la arabización, casi total. ¡En España, se tiene que recomenzar para rerromanizar castellanizando!

A pesar de los síntomas renovadores que se notan poco antes de la ascención al trono de Fernando V de Aragón e Isabel I de Castilla, persisten muchos de tales esquemas medievales; una nobleza y un clero sumamente poderosos con un latín decadente, producto de la ignorancia. ¡Así se regentaban las instituciones educativas! Por tal motivo era necesario reflexionar y discutir en los pilares de la educación, cultura y lengua a partir de dos principios renacentistas: la "emulatio" y la "imitatio" de las "litterae humanae antiquae".

En España, el "clasicismo" era de segunda: no era filológico: la lectura no se hacía en los originales latinos, y la interpretación textual dejaba mucho que desear. No se daba, como en Italia, la "eloquentia auctorum", sino una filosofía práctica de la vida; saber latín no era ni más ni menos que como conocer cualquier otra lengua.

De tal situación se habían dado cuenta, en la misma Edad Media, los autores del Mester de Clerecía; por eso impregnan sus obras literarias romances de reminiscencias clásicas mediante el empleo de latinismos y de cultismos, no sólo léxicos, casi todos extraídos de la cultura libresca y así, Berceo se dirije a un público ignorante, carente de cultura y trata de educarlo con una dosis de una buena formación literaria. Se daba, en la Edad Media, la imprescindible necesidad de estudiar la cultura libresca sobre la base del latín culto para tener acceso a los bienes de la cultura superior; luego, se forma la clase de letrados con dos corrientes: la latina y la románica, cuando éste es tenido en mayor consideración medieval.

Pero, a pesar del Mester de Clerecía, Elio Antonio de Nebrija no pudo dejar de hablar de la "barbaria hispana", a finales del siglo XIV: por eso critica el latín escolar; critica el latín de los nobles; critica el latín eclesiástico; critica al clero y, a las ideas teológicas de éste, se opone el "socratismo cristiano" de Petrarca.

Tal barbarie hispana, según sus mismos detractores, era producto de la corrupción del saber y de la ciencia, debido al decadente nominalismo de los escolásticos tardíos y a la ignorancia de los estudios clásicos, como ya se expuso.

\section{La imitatio y emulatio renacentistas: latín y romance}

La reflexión y renovación del latín resultó también en una re-reflexión y renovación del romance. La primera tarea que se proponen los humanistas españoles, bajo la batuta de Elio Antonio de Nebrija, es recuperar el latín: el clásico; la segunda es consecuencia de ésta: potenciar gramaticalmente la lengua materna según el principio renacentista de la "imitatio" y la "emulatio". De este modo, la reflexión lingüístico-filológica se extendió al campo de las lenguas originadas en el mismo latín: las romances, para que éstas adquirieran la misma sublimidad que la lengua clásica, aunque tales romances procedan del latín vulgar, aspecto que no ignoran los humanistas. Estos no luchan contra el latín vulgar, sino contra el latín medieval: ¡éste es el corrupto! De hecho Bruni y Biondi hablan de la noble vertiente del latín. Los contemporáneos de Nebrija sabían que, desde hacía algunos años, el latín ya no era una lengua natural, y que la naciente literatura se estaba expresando en lengua materna, término acuñado en el siglo XIII; mas, a pesar de los tremendos esfuerzos de los humanistas, el latín va quedando relegado al 
ambiente eclesiástico y académico que ellos mismos habían criticado; ahora, únicamente, se lo estudia según los cánones gramaticales; Nebrija impulsa también el interés del romance según dichos cánones, pues no sólo el latín es digno de arte (sinónimo de doctrina, como cuando se dice "arte poética"); el castellano ya lo iguala; incluso, al mismo griego; el prestigio de las lenguas nacionales corre ahora parejo con el del idioma de Virgilio, y su mayor o menor proximidad depende de su poder imitativo en originalidad; para tal fin, se debe regularizar, mediante la gramática, su estructura, y la lengua no ande por las buenas de Dios: suelta (enunciado que debe ser entendido en un determinado código lingüístico y nunca como nivel general de comunicación).

Así pues, la restauración y renovación del romance, a finales de la Edad Media, o mejor, a principios del Renacimiento, indujeron a la creación de una gramática del romance castellano, por el simple principio de la "emulatio" y de la "imitatio", pues el común de la gente, si no poseía estudios formales, empleaba únicamente el vulgar materno. Más bien, entre los mismos humanistas se crea un ambiente (de ningún modo antilatino) favorable a las lenguas romances, justo allí donde fallan por falta de experiencia intelectual, dada su relativa juventud, lo cual no les impide ser colocadas en el mismo nivel que el latín. El cultivo de éste induce al cultivo del romance, y las mismas teorías aplicadas al estudio del latín se aplican al vulgar materno, máxime que la reina Isabel había encargado a Nebrija traducir al catellano sus "Introductiones" (1488).

La herencia "negativa" del latín medieval, generó, indirectamente, gran interés por el latín áureo, y, al producirse una disparidad con el romance, queda éste revalorizado y renovado; pero, para que esto no se pierda, Antonio de Nebrija lo fija en una gramática escrita, según estos cinco principios a partir de la "emulatio" y la "imitatio" renacentistas:

1. Reflexión del latín > reflexión del romance.

2. Revalorización del latín $>$ revalorización del romance.

3. Renovación del latín $>$ renovación del romance.

4. Fijación gramatical del latín > fijación gramatical del romance.

5. Determinado código del latín > determinado código del romance.

En España, Elio Antonio de Nebrija fue el primero en darse cuenta de las deficiencias del latín en libros como el Doctrinale y el Catholicon y en las gramáticas modistas en otros textos de enseñanza gramatical escolar y universitaria; de las inútiles conclusiones filosóficas; de lo estéril en que se convertía la enseñanza por culpa de éstas, de la ausencia de belleza y estilo en el uso del latín: sin gusto literario ni elaboración artística, pues se había perdido la imaginación, y la elocuencia había decaído. El mal prestigio del latín había calado hondo. El lebrijense estaba consciente de la necesidad de restituir la verdadera latinidad con una referencia al latín clásico, y no al medieval. ¿Por qué no ir a sus fuentes directas?

Por eso había emprendido su viaje a Boloña, donde, luego de haber cursado estudios de latín en su universidad, implantó el saber y el método en el Studium de Salamanca, tomado a la fuerza, como si se tratara de una fortaleza medieval, para desterrar la barbarie imperante en la fecha de su regreso: 1473 .

Nebrija no quiere que a su lengua materna le suceda lo mismo que le había sucedido al latín medieval; por eso encausa el castellano gramaticalizándolo bajo la guía del latín. ¿Acaso 
no se trataba de una lengua neolatina? Pero él se cuida de predicar una relatinización violenta, cruda y absurda. Su visión es, además, práctica y real, pues se basa en los hechos lingüísticos, y así evita que el romance castellano caiga en una relatinización inútil y anacrónica.

\section{Conclusión: el humanismo de Nebrija}

Lo esbozado hasta el presente constituye las ideas esenciales que abrigan Nebrija y algunos coetáneos suyos en el plano de la lengua, sobre todo, en relación con el latín.

A partir de su concepción filológica, desentraña una serie de ideas que hacen de él un "reformador" de su época; su interés por la transformación va impreso con un sello de "humanista".

Esbozo algunas ideas sobre el humanisno de Elio Antonio de Nebrija, para lo cual es imprescindible partir de una definición de esta palabra en su sentido original latino:

El "Humanismo" es un movimiento que se originó en las postrimerías de la Edad Media y en los inicios de la época moderna: en el gran Renacimiento. Predica una actitud idealista de renovación espiritual de toda persona según ideas extraídas de la literatura de los clásicos grecorromanos: el modelo formativo está conformado por las letras humanas en los "Studia humanitatis".

El "Humanismo" se originó en Italia, la patria del latín, uno de cuyos más ardientes defensores fue Francesco Petrarca, quien tuvo una admiración ilimitada por la cultura latina clásica:

1. Antonio Martínez de Xarana emula a los humanistas de Italia e introduce el movimiento en su país: España.

2. En su admiración por el mundo antiguo de Roma, adopta el nuevo nombre de Elio Antonio de Nebrija, hoy, Lebrija, la antigua "Nebrissa Veneris", a la que, aún en su juventud, le dedica su "Salve parva domus".

3. El centro de la atención nebrijiana está dirijido hacia el ser humano y a un aspecto inseparable de éste: el idioma en su aspecto gramatical, que se apoya en el pensamiento; por eso estudia y aprende bien el latín ciceroniano, de donde se origina su interés por la lengua materna, para que adquiera la grandeza de aquél, y así restaurar la antigüedad grecolatina, principalmente, la literatura: donde mejor se refleja el humanismo; e imita la "eloquentia auctorum": los "optimi".

4. El nebrijense se interesa también por la enseñanza del latín metodológicamente, sobre los textos originales, para que la educación, la ciencia y la cultura mejoren entre sus coterráneos.

5. Su preocupación por el latín clásico lo lleva a preocuparse por su romance materno, y viceversa, pues latín y romance no se contraponen: más bien se complementan. En la nueva cultura, la impulsada por los Reyes Católicos, florece también la lengua vulgar, en una ambivalencia "latín-romance". 


\section{Epílogo}

La restauración de la "la latinitas" en España induce a Nebrija a restaurar las letras, incluida su lengua materna, y, en su fijación gramatical, se encuentra también un antídoto contra la barbarie imperante en su época; con la gramática se destierra la ignorancia, pues el idioma es base de toda ciencia y guía de verdad, de donde lo inseparable de escuela-idioma/individuo-sociedad. El idioma presta servicios esenciales: expresa la experiencia vital, por lo cual, el foco de renovación y de perfeccionamiento humano debe ser a partir de la lengua de la nación; por ella se inmortalizan las hazañas de un pueblo, por ella florecen las artes de la paz, si se persuade correctamente. ¡He aquí la (...) "importancia de la educación y de la reforma pedagógica propugnada por el humanismo y de Nebrija como primer humanista español."

Elio Antonio de Nebrija cumple a cabalidad con una de las tareas esenciales del "Humanismo": la reflexión y el estudio idiomáticos, esenciales en toda reforma educativa y humana.

Su reforma idiomática es inconcebible si no se toma en cuenta la intervención, directa o indirecta, positiva o negativa, del idioma humanista por excelencia el LATIN, aspecto afirmado por Quilis:

Cuando Nebrija escribe sus obras gramaticales, no parte de cero. Cuenta con la rica tradición grecolatina, que, en su caso, se circunscribe principalmente a tres gramáticos latinos, que parecen ser su fuente más directa: Prisciano, Diomedes y Donato, sin olvidar a Quintiliano, al que, a veces, llama nuestro. De ellos toma la base teórica y sobre ésta elabora su doctrina (...) (Quilis 1980: 20)

Todas sus obras gramaticales demuestran su sólido conocimiento de los gramáticos latinos y su propia concepción de la teoría y de la estructura de la lengua al elegir en cada caso la solución más conveniente, tanto tomada de las fuentes existentes, como acuñada para el caso en cuestión (...) (Op. cit: 40)

¡Y sobre esta base, Antonio de Nebrija sigue luego su propio camino, según debe ser!...

\section{Bibliografía}

Cano Aguilar, Rafael. 1988. El español a través de los tiempos. Madrid: Arco/Libros S.A.

Carrera De La Red, Avelina. 1984. El "problema de la lengua” en el Humanismo renacentista español. Valladolid: Biblioteca General deValladolid.

Cerda Masso et al. 1986. Diccionario de lingüística. Madrid: Anaya.

Colombo, Celia. 1984. Humanismo y Renacimiento. Madrid: Cencel- Kapeluz.

Curtius Ernest, Robert. 1975. Literatura europea y Edad Media latina. México: Fondo de Cultura Económica. 
Díaz-Echarri, Emiliano y José María Roca Franquesa. 1972. Historia general de la literatura española e hispanoamericana. Madrid: Editorial Aguilar.

García de Diego, Vicente. 1970. "Prólogo". Diccionario ilustrado Latino-español / español-latino. Barcelona: Biblograf S. A.

Herrero, Víctor José. 1965. Introducción al estudio de la filología latina. Madrid: Editorial Gredos.

Highet, Gilbert. sf. La tradición clásica. México: Fondo de Cultura Económica.

Jäger, Gerhard. 1965. Einführung in die klassische Philologie. München: Verlag C.H. Beck.

Jaeger, Werner. 1967. Paideia: los ideales de la cultura griega. México: Fondo de Cultura Económica.

Lamer-Hans y Paul Krohl. 1989. Wörterbuch der Antique. Stuttgart: Kröner Verlag.

Lapesa, Rafael. 1980. Historia de la lengua española. Madrid: Editorial Gredos.

Marín, Diego. 1969. La civilización española. Toronto: University of Toronto Press.

Prezzolini, Giuseppe. 1955. El legado de Italia. Madrid: Ediciones Pegaso.

Quilis, Antonio. 1980. A. de Nerbrija, Gramática de la lengua castellana. Madrid: Editorial Nacional.

Quirós R., Manuel A. ms. El latín y las lenguas romances (Diccionario). San José: Universidad de Costa Rica.

Quirós R., Manuel A. ms. Origen de las universidades y su medio expresivo: el latín. San José: Universidad de Costa Rica.

Renzi, Lorenzo. 1982. Introducción a la filología románica. Madrid: Editorial Gredos.

Remli E. TH. 1967. Historia universal ilustrada. Barcelona: Vergara Editorial. T. I y II.

Riquer, Martin de. 1975. Los trovadores, historia literaria y textos. Barcelona: Editorial Planeta.

Robins H. R. 1974. Breve historia de la lingüística. Madrid: Paraninfo.

Sainz de Robles. 1972. Diccionario de la literatura, términos, conceptos ismos literarios. Madrid: Aguilar. T. I. 
Sapegno, Natalino. 1963. Historia de la literatura italiana. Barcelona: Editorial Labor.

Sellner. s.f. Latein im Alltag. Wiesbaden: VMA-Verlag.

Tagliavini, Carlo. 1981. Orígenes de las lenguas neolatinas. México: Fondo de Cultura Económica.

Thoorens, León. s.f. Roma y la Edad Media latina, Alejandría. Roma. Helenismo y latinidad. El Renacimiento. Madrid: Ediciones Daimon.

Valbuena Prat, Ángel. 1963. Historia de la literatura española. Barcelona: Editorial G. Gili S.A. T. I.

Viscardi, Antonio. 1967. Le letterature d'oc e d'oil. Florencia: Sansoni Editori.

Von Wilpert, Gero. 1964. Sachwörterbuch der literatur. Stuttgart: Kröner Verlag.

Wolff, Philippe. 1971. Origen de las lenguas occidentales 100-1500 d.C. Madrid: Ediciones Guadarrama. 